\title{
Positive behavioral contrast, autoshaping, and omission responding in the goldfish (Carassius auratus)
}

\author{
SARAH W. BOTTJER, STANLEY R. SCOBIE, and JULIA WALLACE \\ State University of New York at Binghamton, Binghamton, New York 13901
}

\begin{abstract}
Two experiments with goldfish were performed to investigate the role of stimulus-reinforcer vs. response-reinforcer relationships in omission training and the role of stimulus localizability in a positive behavioral contrast paradigm. The directed behavior of fish, like that of pigeons and rats in other studies, was greatly influenced by positive stimulus-reinforcer correlations, as evidenced by maintained contacts of a signal for food, even though such responses terminated the signal and cancelled reinforcement delivery. Goldfish exhibited positive behavioral contrast when the signals for reinforcement and nonreinforcement were displayed directly on the response key, but no contrast was observed when variations in a diffuse houselight stimulus were used as signals for reinforcement or nonreinforcement. Analysis of sequentialtrial data yielded effects analogous to Pavlovian positive and negative induction. Theoretical and methodological problems were briefly considered.
\end{abstract}

Positive behavioral contrast was defined by Reynolds (1961) as an increase in response rate during the unchanged component of a multiple schedule when there is a rate decrease in a changed component; "change" might refer to the introduction of extinction, a leaner reinforcement schedule, or a schedule requiring a low rate of responding.

Although there have been numerous demonstrations of positive behavioral contrast in pigeons, to our knowledge there have been none in goldfish. Such a demonstration would complement existing data which indicate that simultaneous, but not successive, contrast can be obtained in goldfish (Mackintosh, 1974, p. 394). For instance, Cochrane, Scobie, and Fallon (1973) and Gonzalez and Powers (1973) obtained clear evidence of negative simultaneous contrast: Fish that were differentially reinforced with large and small rewards showed inferior performance during trials involving the small reward as compared to a control group that was nondifferentially reinforced with the small reward throughout training. However, these two studies, as well as that of Gonzalez, Potts, Pitcoff and Bitterman (1972), found no evidence for negative successive contrast in

This research was supported by National Institute of Mental Health Grants MH-19661, MH-19300, and MH-27210. The paper is based on a thesis submitted by Sarah Bottjer to the Department of Psychology, SUNY-Binghamton, in partial fulfillment of the requirements for the B.A. degree with honors. Reprints of the article may be obtained from Sarah Bottjer, Department of Psychology, Indiana University, Bloomington, Indiana 47401. Julia Wallace is now at the Department of Psychology, Princeton University, Princeton, New Jersey 08540 . We would like to express our thanks to Eliot Hearst for his helpful criticisms of this paper. goldfish. That is, fish that were trained initially with a large reward showed little or no decrement in performance when shifted to a smaller reward, relative to a control group that received the smaller reward throughout training. With rats, however, both types of contrast effect (simultaneous and successive) are readily obtained (Mackintosh, 1974, p. $387 \mathrm{ff}$ ). Since the paradigms for negative simultaneous contrast and positive behavioral contrast are highly similar (i.e., both allow the subject to experience each reward magnitude within a single session), it seems likely that goldfish will demonstrate positive behavioral contrast.

The type and location of the signals employed in studies of behavioral contrast are important factors. Pigeons pecking keys on which the discriminative signals are displayed show large contrast effects, whereas diffuse, nonlocalized signals such as tones or houselights have not been consistently effective in producing positive contrast with the keypecking response. Redford and Perkins (1974) and Schwartz (1975), for example, obtained positive behavioral contrast when the discriminative stimuli were localized on the response key, but not when houselights were used as discriminative stimuli. Although Hearst and Gormley (1976) obtained rate increases to a key during a houselight $\mathrm{S}+$, these increases were not greater than those in subjects that did not exhibit discrimination learning. On the other hand, Farthing (1975), Hemmes (1973), and Westbrook (1973) did obtain small rate increases during $S+$ with diffuse stimuli. In addition, positive contrast has occasionally been obtained in rats when diffuse stimuli are used (Gutman, Sutterer, \& Brush, 1975; Mackintosh, Little, \& Lord, 1972; Wilkie, 1972; but see also Pear \& Wilkie, 1971). 
The main focus of our work was to provide a demonstration of positive behavioral contrast in goldfish, and to determine the potential effects of stimulus localizability on the contrast effect. Gamzu and Schwartz (1973) pointed out that positive behavioral contrast paradigms involve the introduction of a differential stimulus-reinforcer relation, and suggested that autoshaped responses, elicited during the discrimination phase of a behavioral contrast paradigm, are responsible for the contrast effect. This explanation accounts for the fact that positive contrast is most prominent when the stimulus which signals impending reinforcement or nonreinforcement is also the stimulus at which responses are directed, and is attenuated when the signals are diffuse and removed from the response manipulandum.

\section{EXPERIMENT 1}

Since autoshaped responses may contribute to positive behavioral contrast, we wanted, first, to establish the sensitivity of goldfish's directed behavior to a stimulus-reinforcer correlation, as has been done for pigeons and rats. Our objective was to provide another demonstration of autoshaped responding to a key manipulandum, and to determine whether fish would continue to respond under an omission training procedure. In omission training, a positive stimulusreinforcer correlation and a negative responsereinforcer contingency are pitted against each other. Even though responding prevents presentation of food in this paradigm, animals frequently continue to respond to the signal for reinforcement (Hearst \& Jenkins, 1974; Schwartz \& Williams, 1972; Williams \& Williams, 1969).

\section{Subjects \\ Method}

Six large, experimentally naive goldfish (Carassius auratus), obtained from Ozark Fisheries of Stoutland, Missouri, served as subjects. They were $10-12 \mathrm{~cm}$ in length, and were housed in individual 8.5 -liter tanks.

\section{Apparatus}

The apparatus was similar to that described by Bitterman (1966). An intelligence panel contained two nose-press manipulanda of translucent Plexiglas, $2.5 \mathrm{~cm}$ in diameter, which could be illuminated with red, green, or white light. In all experiments to be reported, only the right-hand key was used. Keypresses were detected by a piezoelectric crystal (phonograph cartridge) attached to the response key. This velocity-sensitive transducer was calibrated to respond to a threshold force generated by a $.50 \mathrm{~g}$ pendulum with a radius of $12 \mathrm{~cm}$ swinging through an arc of $14^{\circ}$. This calibration was done in air, and key sensitivity is somewhat different in water, due to water's damping effect. The luminance of the light on the key was $5.5 \mathrm{fL}\left(18.8 \mathrm{~cd} / \mathrm{m}^{2}\right)$. The houselight was located on a Plexiglas shelf, $22.0 \mathrm{~cm}$ above the floor. Houselight illumination, measured in front of the response key, was $1.5 \mathrm{fc}(16.2 \mathrm{~lx})$. The feeder mechanism, located in the midline of the panel, $3.5 \mathrm{~cm}$ below and $4.5 \mathrm{~cm}$ left of the response key, consisted of a clear Plexiglas nipple which was shielded by a $2.5-\mathrm{cm}$-diam Plexiglas disk with a small hole in its center. The feeder could be illuminated with red, green, or white light. When the feeder disk was removed, the feeder nipple could be released from a stationary position and contacts with the feeder nipple could be recorded. Semiliquid food $(1.0 \mathrm{ml}$ contained $75.0 \mathrm{mg}$ dry Tetramin fish food in a starch solution) was pumped through plastic tubing to the feeder nipple. One reinforcement consisted of $.02 \mathrm{ml}$ of food delivered over a 2 -sec period, during which time the feeder disk was illuminated with white light. Four experimental boxes were housed in sound-attenuating chambers in a sound-shielded room. Control and recording equipment were located in a separate room.

\section{Procedure}

All fish were given either 1 or 2 days of feeder training prior to the start of the experiment proper. During these sessions, the keylight remained darkened and the houselight was constantly illuminated with white light. Reinforcements were presented randomly with respect to the fish's position in the chamber until the fish was approaching the feeder with a latency of 1-2 sec whenever food was delivered. Throughout the experiment, all fish were given supplementary feeding after sessions so that their total daily intake was approximately $1.25 \mathrm{ml}$ of food.

Autoshaping. All fish were then randomly assigned to one of two groups. One group, the Keylight group, received pairings of key illumination with food presentation; the other group, the Feeder group, received pairings of feeder illumination with food presentation. The Feeder group is analogous to a group tested by Woodard and Bitterman (1974), and represents an attempt to replicate their findings (i.e., directed responding to the feeder). For both groups, the signals consisted of 20 -sec illumination with red light of either the keylight or the feeder light, respectively. Offset of the signal was simultaneous with food presentation. For both groups, no response contingency was in effect, and responses to the appropriate manipulandum (key or feeder nipple, respectively) were recorded but had no scheduled consequences.

A session consisted of 21 trials separated by a mean intertrial interval of $90 \mathrm{sec}$ (range $=45-135 \mathrm{sec}$ ). Fish in the Feeder group first received three daily sessions of training. However, since these three subjects showed a strong tendency to respond to the feeder indiscriminately throughout all sessions, they were shifted to the Keylight condition for an additional four sessions of training. Fish in the Keylight group were given three daily sessions of training, after which they were not tested for 3 days, and then were given one additional session (which coincided with the last session for the Feeder group shifted to the Keylight condition).

Omission training. The six fish were then randomly reassigned to one of two experimental conditions, with the restriction that no more than two fish from one of the initial groups could be assigned to a new experimental condition. The two groups of this part of the experiment were labeled Extinction and Omission. For the Extinction group, a response to the illuminated key turned off the stimulus, and no food was presented. Failure to respond to the key resulted in a trial terminating after $20 \mathrm{sec}$, with no food presented. For the Omission group, a response to the illuminated key also turned off the stimulus, and no food was presented; however, on trials during which no response occurred, the trial was terminated after $20 \mathrm{sec}$ and was followed immediately by food delivery, as in the first phase of the experiment. Both groups were tested for 14 daily sessions on their respective procedures.

\section{Autoshaping}

\section{Results and Discussion}

The autoshaping data are shown in the left-hand panel of Figure 1. Values on the ordinate represent the percentage of trials on which at least one response oc- 


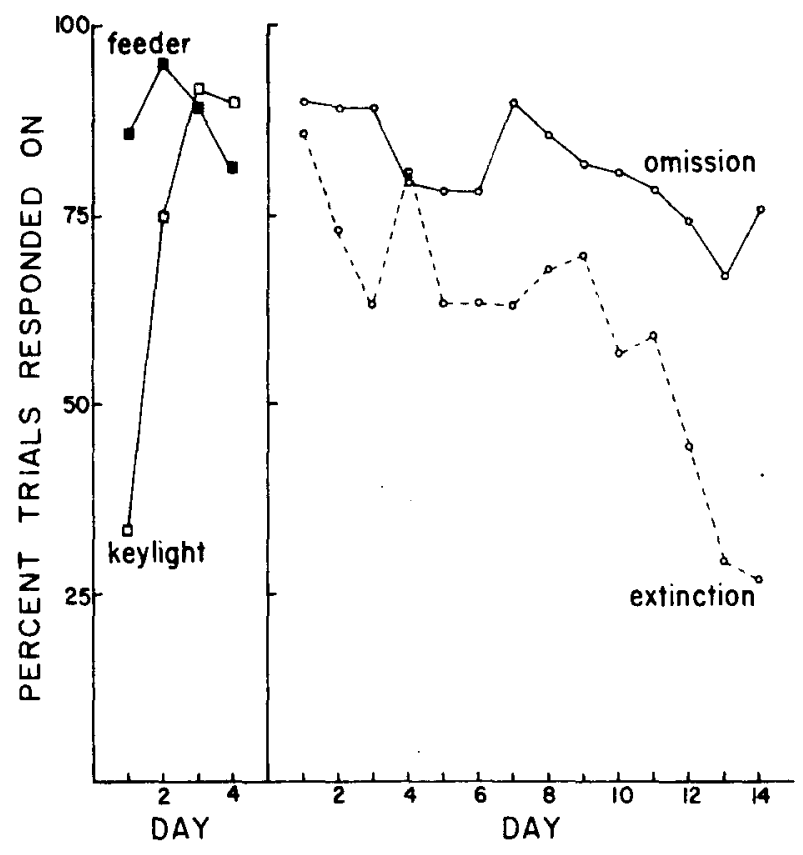

Figure 1. Percent trials with at least one keypressing response for the Feeder and Keylight groups (left panel) and the Omission and Extinction groups (right panel) of Experiment 1.

curred. As training progressed, the Keylight group showed a rapid increase in the number of trials with a response. The Feeder group showed a high level of responding to the key as soon as the signal was presented at that location. There was no evidence of gradual acquisition of responding to the key, which suggests that these fish may have formed an association between the red illumination and food which was not evident in their prior performance (responding to the feeder).

\section{Omission Training}

The right-hand panel of Figure 1 shows that the fish in the Omission group continued to respond on a substantial majority of the trials; throughout omission training, the mean percentage of trials with responses for all fish in this group was 83.0 (range $=78 \%-91 \%$ ), which resulted in a reduction of the obtained reinforcements to $17.0 \%$ (range $=22 \%-9 \%$ ). The Extinction group, on the other hand, demonstrated a slow, gradual decrease in the number of trials with a response. During each of the last 6 days of this phase there was no overlap between individual subjects in the two different groups, $\mathrm{t}(4)=10.0, \mathrm{p}<.001$.

Because no control condition was included to assess the effect of contingent pairings of the signal with food, the acquisition of keypressing cannot be unequivocally attributed to that contingency. However, the results of the second part of this experiment indicate that the maintenance of responding to an illuminated key under an omission training procedure is mainly due to the signal-reinforcer, as opposed to the response-reinforcer, relationship. The only experimental difference between the Omission and Extinction groups was the pairing of food with the keylight when no responding occurred. In the Omission group, the few trials on which such pairings did occur were apparently sufficient to sustain a significantly higher level of responding than that in the Extinction group, for which no stimulus-reinforcer pairings ever occurred.

\section{EXPERIMENT 2}

The results of Experiment 1 indicated that goldfish react to autoshaping procedures in much the same way as pigeons. Thus, an investigation of the role of stimulus localizability in positive behavioral contrast was in order. If processes like those involved in autoshaping are mainly responsible for contrast, then moving the signal away from the response manipulandum and making it more diffuse ought to eliminate or greatly reduce "extra" responses due to the stimulus-reinforcer correlation and thus eliminate or attenuate contrast (e.g., Hearst \& Gormley, 1976).

To examine this possibility, different groups of fish were tested in a behavioral contrast paradigm with either localized (keylight) or diffuse (houselight) stimuli. Independent control fish were tested in a similar, but nondiscriminative, paradigm in order to assess rate increases that could occur in the absence of discrimination training. The diffuse stimulus was "localizable" in the sense that its source was discernible, but it differed from the localized stimulus condition in two ways: (a) it was not confined to a discrete area, and (b) the stimulus to which responding was directed (the keylight) was located away from the diffuse stimulus (whereas in the localized stimulus condition these two stimuli were identical).

Subjects

\section{Method}

Sixteen experimentally naive goldfish of the same type as in Experiment 1 served. Twelve of the fish were $7.8 \mathrm{~cm}$ in length, and the remaining four were $10-12 \mathrm{~cm}$ long. All were housed and fed as in Experiment 1.

\section{Apparatus}

The apparatus was the same as in Experiment 1.

\section{Procedure}

Preliminary training. All fish were feeder trained as in Experiment 1 . As soon as a fish was eating readily whenever the feeder operated, it was manually shaped to press the key, which was constantly illuminated with white light. After hand shaping was completed, all fish were allowed to earn 50-60 reinforcements on each of 2 successive days. The key was again illuminated with constant white light, and each response was reinforced.

Two days of pretraining preceded the experiment proper. On the first day, all fish were allowed to earn approximately 50 reinforcements, with each response reinforced during a series of discrete $60-\mathrm{sec}$ trials. Trials, separated by a 3 -sec period of total darkness, consisted of the illumination of both the houselight and the keylight with white light. The same procedure 
was followed on the second day of pretraining, except that the schedule of reinforcement was gradually increased to variable interval $15 \mathrm{sec}$. On the basis of their performance during these 2 pretraining days, the subjects were assigned to three matched groups of 5 or 6 subjects each. The first two groups were assigned to a localized stimulus (Keylight) condition, while the third was assigned to a diffuse stimulus (Houselight) condition. Matching of groups was accomplished by random assignment of the three fish with the highest rate of responding to the three groups, then the three fish with the next highest rate of responding, and so on.

Nondifferential training. Day 1 began with the gradual introduction of a multiple VI $30-\mathrm{sec}$ VI $30-\mathrm{sec}$ schedule and the introduction of the experimental stimuli for the first time. Variable interval reinforcements were programmed according to the sequence given in Fleshler and Hoffman (1962), with the exception that there was a 3-sec minimum interval between reinforcements. During trials for the Keylight group, the key was illuminated with either constant or flashing white light (1.5 flashes of $100-\mathrm{msec}$ duration per second) while the houselight remained constantly illuminated with white light. During trials for the Houselight group, the houselight was illuminated with either constant or flashing white light, while the keylight remained constantly illuminated. For half the subjects, a flashing light signaled reinforcement during subsequent discrimination training ( $S_{1}$, referred to as $S+$ during discrimination training) and a constant light signaled nonreinforcement during subsequent discrimination training $\left(S_{2}\right.$, referred to as $S$ - during discrimination training), whereas for the remaining subjects the signals were reversed. Signals were presented in accordance with orders selected from Vandament, Burright, Fessenden, and Barker (1970) to yield four different trial types (for sequential analyses during subsequent discrimination training): positive trials preceded by positive trials $(S+\mid S+$ ), positive trials preceded by negative trials $(S+I S-)$, negative trials preceded by positive trials $(S-\mid S+)$, and negative trials preceded by negative trials $(\mathrm{S}-\mathrm{IS}-$ ).

Nondifferential training included 16 daily sessions of 25 trials each. The first trial of every session was always an $S_{1}$ trial, whereas the remaining 24 (six of each of the four types of trials) consisted of $12 \mathrm{~S}_{1}$ and $12 \mathrm{~S}_{2}$ trials. As in pretraining, trials consisted of $60-\mathrm{sec}$ stimulus periods separated by a 3-sec period of darkness. A VI 30-sec schedule was in effect during both $S_{1}$ and $S_{2}$ for both groups throughout this phase. Nondifferential training continued until every fish had reached a criterion of stability in rate of responding (less than $10 \%$ change in mean rate of responding between two 3-day blocks), which required 16 sessions.

Discrimination training. The 10 subjects in the two Keylight groups were again matched for rate of responding in $S_{1}$ and $S_{2}$ combined and assigned to an experimental (Keylight) group and a control (Keylight Control) group. One subject from the Houselight condition was chosen as a control subject (Houselight Control), while the remaining five subjects constituted a second experimental (Houselight) group. (We decided to assign only one subject to the Houselight Control condition in order to maintain an adequate number of subjects in the three remaining conditions.) Discrimination training began on Day 17 and consisted of an additional 16 daily sessions of 25 trials each, as in nondifferential training. For all control fish, the schedule of reinforcement was unchanged. For the two experimental groups, the schedule of reinforcement in $S_{2}$ was changed to extinction.

Return to nondifferential training. This phase began on Day 33 and continued for 7 days, during which time the two experimental groups were returned to a multiple VI $30-\mathrm{sec}$ VI $30-\mathrm{sec}$ schedule, while the control fish remained on this nondifferential schedule.

\section{Results}

An overall analysis of variance was performed on the mean response rates for all fish over the last 10 days of nondifferential training with signal type (constant vs. flashing) as a repeated measure. This analysis yielded no main effect of Signal Type, $F(1,12)=2.62, p>.10$. A similar analysis was performed on the data from the discrimination phase, which also included the effect of $S_{1}(S+)$ and $S_{2}(S-)$. This analysis also yielded a nonsignificant effect of Signal Type, $F<1$, and of all interactions including Signal Type. Therefore, all subsequent analyses were collapsed across signal type.

\section{Nondifferential Training}

The left-hand panels of Figure 2 show that training under the localized stimulus (Keylight) condition resulted in a tendency for these subjects to respond at a higher rate (in $S_{1}$ and $S_{2}$ combined) than subjects in the nonlocalized (Houselight) condition. However, the effect was not statistically reliable: In an analysis of variance utilizing the last 15 days of this phase as a repeated measure, the effect of Stimulus Condition (Keylight vs. Houselight) approached significance, $F(1,14)=3.34, p<.10$. A significant effect of Days, $F(4,56)=5.47, p<.001$, was obtained, indicating a gradual increase in response rate over days.

\section{Discrimination Training}

The upper and lower center panels of Figure 2 show the data from this phase for the Houselight and Keylight groups, and their respective controls, separately.

$S+$ responding. The lower center panel of Figure 2 shows that the shift to differential reinforcement produced a substantial contrast effect in the Keylight group.

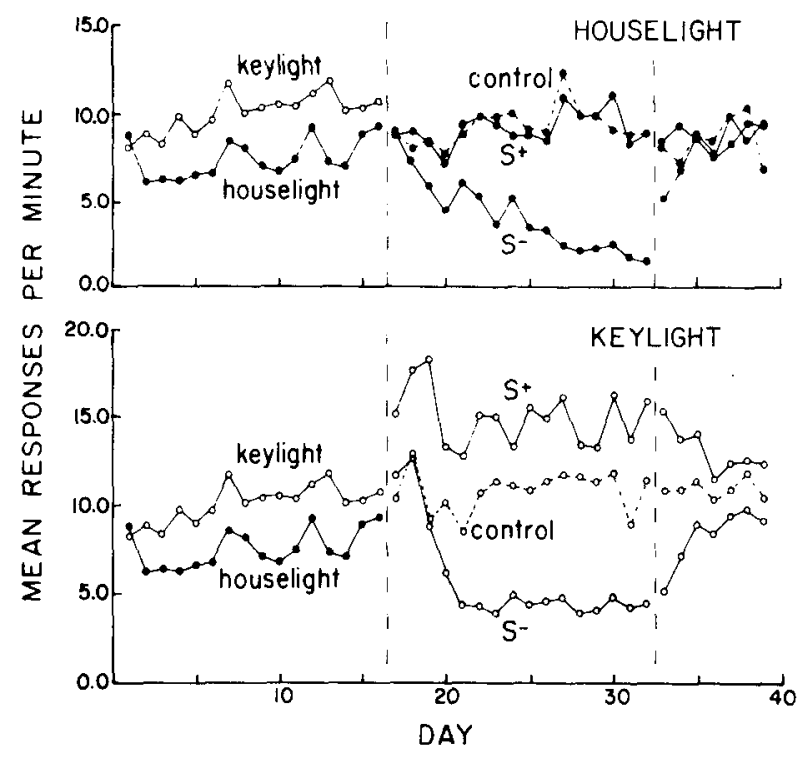

Figure 2. Mean response rate for the Houselight and Keylight groups of Experiment 2. Left panels show nondifferential training for both conditions (same data are plotted above and below to facilitate comparison with subsequent phases). Middle panels show discrimination training for the Houselight (upper) and Keylight (lower) groups. Right panels show return to nondifferential training. Note: Dashed line labeled "control" in Houselight panel represents data from only one subject. 
That is, the Keylight group showed a greatly increased rate of responding in $S+$ over the first 3 days of this phase, relative to its baseline as well as to its control group. After the first 3 days, the rate of responding in $\mathrm{S}+$ declined, but the increased responding continued throughout this phase. The control group remained at about the same level as it had been. The upper center panel of Figure 2 shows no evidence of contrast in the Houselight group. In spite of the fact that there was only one control fish for this condition, the overlap of responding in $\mathrm{S}+$ for the Houselight group with this one subject, and the lack of change from the previous, nondifferential phase are consistent with a failure to observe a contrast effect.

Separate, multifactor repeated-measures analyses of variance were performed for each experimental condition. Contrast was defined as a change in rate of responding in experimental animals between nondifferential and discriminative stages of training relative to a change in rate in control animals during the same sessions. Rate of responding in $S_{1}$ and $S_{2}$ were averaged for control animals, as there were no differences between them, $\mathrm{t}<1$. The analysis for the Keylight group and its control yielded a significant Groups by Stages interaction, $F(1,8)=11.11, p<.01$, indicating that the contrast effect evident in the lower panel of Figure 2 was reliable. In order to test the stability of the contrast effect over time, a $t$ test was performed on the mean rate of responding for each subject over the last 3 days of discrimination training. This analysis yielded only a marginally significant difference between the Keylight group and its control, $\mathrm{t}(8)=2.05, \mathrm{p}<.10$. Due to the fact that there was only one Houselight Control animal, the analysis for the Houselight group included the data from the Keylight Control group, which was stable over stages and therefore an appropriate statistical comparison condition, to yield an experimental group of $n=5$ and a control group (including all control fish) of $n=6$. Since contrast was defined as a change in rate of responding of a shifted group, relative to an unshifted group, the absence of a significant interaction would indicate that there was no significant contrast effect for the Houselight group. This analysis yielded no significant effects [for the Groups by Stages interaction, $\mathrm{F}(1,9)=2.77, \mathrm{p}>.10]$.

S- responding. An analysis of variance utilizing Days as a repeated factor over the first 6 days of discrimination training (by which time rate of responding in the Keylight group appeared to have stabilized) was performed in order to test for differences between the two groups in rate of learning the discrimination. A significant Days by Groups interaction was found, $F(5,40)=$ $3.05, \mathrm{p}<.025$, indicating that the Keylight group decreased its rate of responding to $S$ - faster than the Houselight group. There was no difference between groups, $\mathrm{F}<1$, and there was a highly significant effect of Days, $F(5,40)=10.84, p<.001$, indicating clearly the important fact that both groups did learn the dis. crimination.

\section{Return to Nondifferential Training}

The right-hand panels of Figure 2 show the changes in responding to $S+$ and $S-$ as a result of the shift back to nondifferential reinforcement. The failure to obtain a contrast effect in the Houselight group during discrimination training was supported by the absence of any change in responding to $S+$ when baseline conditions were reinstituted. However, the same was not true of the performance of the Keylight group, which demonstrated a decrease in responding to the former $S+$ during this phase. A $t$ test for related measures performed on the mean rate of responding for each subject during the last 3 days of discrimination and nondifferential training revealed that a change in response rate during $S+$ was significant in the Keylight group, $t(4)=3.07, p<.05$, but not in the Houselight group, $t(4)=1.23, \mathrm{p}>.20$.

\section{Sequential Analyses}

The data for the last 3 days of the discrimination phase are shown in Figure 3 as a function of the four trial types of each session: $\mathbf{S}+|\mathrm{S}+, \mathrm{S}+| \mathrm{S}-, \mathrm{S}-\mid \mathrm{S}+$, $S-\mid S-$. Each of the four types of trials was averaged over these 3 days for each one of three successive $20-\mathrm{sec}$ components of a trial. Thus, the three points on the abscissa represent data from the first, second, and third portion of different trial types, respectively. The corresponding trials for the control fish were analyzed in similar fashion, but due to the fact that there were no differences between them, they were collapsed across all trials and are included in Figure 3 for comparison.

In the Keylight group (left-hand side of Figure 3), the type of trial which preceded a positive trial exerted a substantial effect on responding, with a previous $\mathrm{S}$ trial engendering a higher rate of responding. Thus, this effect was contributing to the overall contrast effect obtained. However, responding on St trials preceded by $\mathrm{S}+$ trials was also higher than the control level. The $\mathbf{S}+$ curves also show that rate of responding varied as a function of trial component. For both types of $\mathrm{S}+$ trial, responding was highest in the first component, showed a drop-off in the middle component,

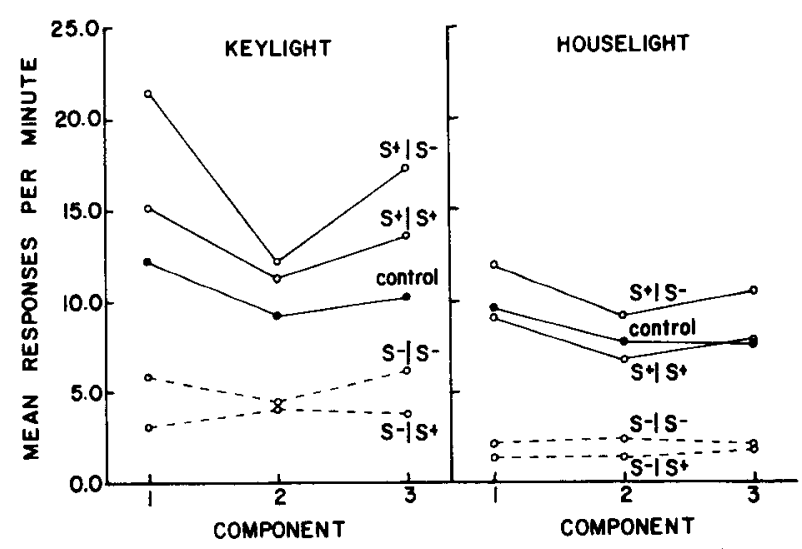

Figure 3. Mean response rate as a function of the four different trial types for experimental groups during discrimination training in Experiment 2 (see text for further explanation). 
and rose again during the third component. This general trend was more pronounced for $\mathbf{S}+\mathbf{S}$ - trials. An examination of comparable data from the nondifferential phase (when all trials signaled reinforcement) revealed no such temporal discrimination.

A within-subjects analysis of variance performed on the two types of $S+$ trials for the Keylight subjects yielded significant effects for Trial Type, $F(1,4)=12.25$, $\mathrm{p}<.025$, and Trial Component, $\mathrm{F}(2,8)=22.40$, $\mathrm{p}<.001$, but not their interaction, $F(2,8)=4.10$, $\mathrm{p}>.05$. Thus, responding during $\mathrm{S}+\mid \mathrm{S}-$ trials was significantly faster than during $\mathrm{S}+\mathrm{S}+$ trials, and the change in rate of responding among trial components was also reliable. A between-subjects analysis of variance performed on $\mathbf{S}+\mathbf{S}+$ trials for the Keylight group vs. the corresponding trials for its control group yielded a nonsignificant effect, $F(1,8)=2.46, p>.10$.

A within-subjects analysis of variance performed on the two types of S-trials yielded no significant effects, although the effect of Trial Type approached significance, $F(1,4)=6.40, p<.10$ [for Trial Component, $\mathrm{F}<1$; for Type by Component, $\mathrm{F}(2,8)=2.45, \mathrm{p}>.10$ ] The question arises here as to whether the differences due to preceding trials are due to a proactive "inhibitory" effect of reinforcement or to a "frustrating" effect of nonreinforcement on subsequent trials. The latter notion seems the more plausible one in this case, due to the interaction of the curve for the control group with the $\mathrm{S}-\mathrm{IS}+$ curve of the experimental group. The form of the interaction is such that, in Component 1 , negative trials preceded by positive trials showed a lower rate of responding, but the same was not true for the control group, which showed a tendency towards increased responding in the first component, even though reinforcement could be obtained on all previous trials, $\mathrm{F}(2,8)=12.83, \mathrm{p}<.01$.

Trial data for the Houselight group are shown in the right-hand side of Figure 3. There is a tendency for the $S+$ curves to differ here, with more responding during $\mathbf{S}+\mid \mathbf{S}-$ trials. In addition, there is a slight temporal trend over trials, similar to that found for the Keylight group. However, a within-subjects analysis of variance showed that neither of these effects was significant, although the effect of Trial Type approached significance, $F(1,4)=4.61, p<.10$ [for Trial Component, $F(2,8)=2.87, p>.01 ;$ for Type by Component, $F<1]$.

There were obviously no differences between the two types of $\mathbf{S}$ - trial for the Houselight group, and no indication of any changes in responding over trial components, although the low rate of responding would have prohibited any such tendencies from appearing.

\section{GENERAL DISCUSSION}

The results of our first experiment indicated that the directed behavior of goldfish is greatly influenced by positive stimulus-reinforcer correlations-that is, in spite of the fact that a negative response-reinforcer contingency was in effect, the fish continued to respond on approximately $80 \%$ of all trials during omission training. This persistent responding presumably reflects the prepotency of conjunctions of signal and reinforcer, as opposed to those of response and reinforcer, in controlling behavior in this situation. However, the fact that a slight decline in responding seemed to be obtained during the course of omission training may indicate that the response-reinforcer contingency was exerting some (perhaps increasing) degree of control. Decrements in responding under omission procedures have sometimes been obtained in pigeons (Hearst, 1975; Schwartz \& Williams, 1972).

The results of Experiment 2 show clearly that goldfish demonstrate positive behavioral contrast, and are consistent with the findings of pigeon studies which reveal little or no contrast when a diffuse stimulus is used as a signal for reinforcement. This demonstration of positive behavioral contrast seems consistent with the overall pattern of results with goldfish: Negative successive contrast is difficult or impossible to demonstrate in fish, whereas positive behavioral contrast and negative simultaneous contrast are easily obtained. As mentioned previously, the paradigms for the latter two phenomena differ from that for the former one in that they allow the subject to experience both reinforcement conditions within a single session, while variations in magnitude of reinforcement are experienced only between stages in a negative successive contrast experiment. Speculation about the theoretical implications of interspecies differences as a function of simultaneous vs. successive contrast has been provided by Bitterman (1975) and Mackintosh (1974, p. 387 ff).

Although the results of this study are consistent with an interpretation of positive behavioral contrast which emphasizes the contribution of autoshaped responses elicited during discrimination training (Schwartz \& Gamzu, 1977), they are also consistent with alternative theoretical explanations. For example, Gonzalez and Champlin (1974) hypothesized that positive behavioral contrast represented a primary (unconditioned) frustrative reaction to an unconfirmed expectation of reward, manifested as an increase in responding to subsequent presentations of the stimulus correlated with reward. The greatly increased rate of responding that was exhibited by the Keylight group over the first 3 days of discrimination training seems to be consistent with such a notion. However, the fact that response rate was maintained at a high level relative to the control group and to the baseline level of responding suggests that autoshaped responses were contributing to the increased rate of responding.

One aspect of our data which should be emphasized is the effect of immediately preceding trials on subsequent trials. Clearly, negative trials were exerting an energizing effect on immediately following positive trials. This effect represents an instance of what Pavlov (1927, p. $188 \mathrm{ff}$ ) termed positive induction. Amsel (1971) has pointed out that positive induction seems to be analogous to the effect of frustration, a term 
which is also applied to increments in responding following the presentation of a stimulus correlated with nonreinforcement. However, we also observed an effect analogous to Pavlovian negative induction-the relatively lower rate of responding on $\mathbf{S}-$ trials preceded by $\mathbf{S}+$ trials. Conceivably, this effect may also represent a "frustrative," balking reaction, just as positive induction may reflect a "frustrative," energizing reaction. The facilitating effect of $S$ - seemed to be relatively permanent, a result which was also reported by Pavlov in some instances (1927, p. 196). The enduring effect of negative trials on immediately following positive trials suggests that this effect was not a primary aversive reaction to an unconfirmed expectation of reward.

Finally, some mention of the appropriate control conditions to evaluate the occurrence of positive behavioral contrast should be made. Subjects in our control conditions received twice as many reinforcements as subjects in our experimental conditions. Thus, our design did not equate subjects for changes in patterning of reinforcement delivery during discrimination training. An alternative control group would be one in which an extended blackout was introduced in place of $\mathrm{S}-$. Hearst and Gormley (1976) found that such a condition yielded substantial rate increases. They pointed out that such enhanced responding would be predicted by the results of autoshaping experiments, since extended blackouts lengthen the intertrial interval, which should facilitate autoshaped responding. Another possible control group would be one that continued to receive presentations of $S_{1}$ and $S_{2}$, but that received the same number of reinforcement presentations as the experimental group (i.e., reinforcements could be obtained during half of both $S_{1}$ and $S_{2}$ presentations). Such a condition would equate experimental and control subjects for changes in reinforcement patterning, as well as for total number of stimulus and reinforcement presentations.

\section{REFERENCES}

Amsel, A. Positive induction, behavioral contrast, and generalization of inhibition in discrimination learning. In H. H. Kendler \& J. T. Spence (Eds.), Essays in neobehaviorism. New York: Appleton-Century-Crofts, 1971.

Bitterman, M. E. Animal learning. In J. B. Sidowski (Ed.), Experimental methods and instrumentation in psychology. New York: McGraw-Hill, 1966.

Bitrerman, M. E. The comparative analysis of learning. Science, 1975, 188, 699-709.

Cochrane, T. L., Scobie, S. R., \& Fallon, D. Negative contrast in goldfish. Bulletin of the Psychonomic Society, 1973, 1 , 411-413.

FARThING, G. W. Behavioral contrast in pigeons learning an auditory discrimination. Bulletin of the Psychonomic Society, 1975, 6, 123-125.

Fleshler, M., \& Hoffman, H. S. A progression for generating variable interval schedules. Journal of the Experimental Analysis of Behavior, 1962, 5, 529-530.

GamzU, E., \& Schwartz, B. Maintenance of key-pecking by stimulus-contingent and response-independent food presentation. Joumal of the Experimental Analysis of Behavior, 1973. 19. 65-72.
Gonzalez, R. C., \& Champlin, G. Positive behavioral cuntrast, negative simultaneous contrast and their relation to frustration in pigeons. Journal of Comparative and Physiological Psychology, 1974, 87, 173-187.

Gonzalez, R. C., Potts, A., Pitcoff, K., \& Bitterman, M. E. Runway performance of goldfish as a function of complete and incomplete reduction in amount of reward. Psychonomic Science, 1972, 27, 305-307.

Gonzalez, R. C., \& Powers, A. S. Simultaneous contrast in gold fish. Animal Learning \& Behavior, 1973, 1, 96-98.

Gutman, A., Sutterer, J. R., \& Brush, F. R. Positive and negative behavioral contrast in the rat. Journal of the Experimental Analysis of Behavior, 1975, 23, 377-383.

Hearst, E. Pavlovian conditioning and directed movements. In G. H. Bower (Ed.), The psychology of learning and motivation: Advances in research and theory (Vol. 9). New York: Academic Press, 1975.

Hearst, E., \& GoRmLey, D. Some tests of the additivity (autoshaping) theory of behavioral contrast. Animal Learning \& Behavior, 1976, 4, 145-150.

Hearst, E., \& Jenkins, H. M. Sign-tracking: The stimulusreinforcer relation and directed action. Austin, Tex: The Psychonomic Society, 1974.

Hemmes, N. Behavioral contrast in pigeons depends on the operant. Journal of Comparative and Physiological Psychology, 1973, 85, $171 \cdot 178$.

MaCkINTOSH, N. J. The psychology of animal learning. New York: Academic Press, 1974.

Mackintosh, N. J., LitTle, L., \& LoRD, J. Some determinants of behavioral contrast in pigeons and rats. Learning and Motivation, 1972, 3, 148-161.

Pavlov, 1. P. Conditioned reflexes. London: Oxford University Press, 1927.

PEAR, J. J., \& Wilkie, D. M. Contrast and induction in rats on multiple schedules. Journal of the Experimental Analysis of Behavior, 1971, 15, 289-296.

Redford, M. E., \& Perkins, C. C. The role of autopecking in behavioral contrast. Journal of the Experimental Analysis of Behavior, 1974, 21, 145-150.

REYnolds, G. S. Behavioral contrast. Journal of the Experimental Analysis of Behavior, 1961, 4, 57-71.

SCHWARTZ, B. Discriminative stimulus location as a determinant of positive and negative behavioral contrast in the pigeon. Journal of the Experimental Analysis of Behavior, 1975, 23, 167-176.

Schwartz, B., \& GamzU, E. Pavlovian control of operant behavior: An analysis of autoshaping and of interactions between multiple schedules of reinforcement. In W. K. Honig \& J. E. R. Staddon (Eds.), Handbook of operant behavior. New York: Prentice-Hall, 1977.

Schwartz, B., \& Williams, D. R. The role of the response-reinforcer contingency in negative automaintenance. Journal of the Experimental Analysis of Behavior, 1972, 17, 351-357.

Vandament, W. E., Burright, R. G., Fessenden, R. R., \& BARKER, W. H. Tables of event sequences for sequential analyses of data in psychological experiments. Behavior Research Methods \& Instrumentation, 1970, 2, 290-296.

WESTBRoOK, R. F. Failure to obtain positive contrast when pigeons press a bar. Joumal of the Experimental Analysis of Behavior, 1973, 20, 499-510.

WILKIE, D. M. Variable-time reinforcement in multiple and concurrent schedules. Journal of the Experimental Analysis of Behavior, 1972, 17, 59-66.

Williams, D. R., \& Williams, H. Auto-maintenance in the pigeon: Sustained pecking despite contingent nonreinforcement. Journal of the Experimental Analysis of Behavior, 1969, 12, 511-520.

Woodard, W. T., \& Bitterman, M. E. Autoshaping in the goldfish. Behavior Research Methods \& Instrumentation, 1974, 6, 409-410.

(Received for publication August 10, 1976; revision accepted April 25, 1977.) 